Original Research Article

\title{
Efficacy of Vitamin $C$ and Vitamin $E$ as an add on therapy in diabetic foot ulcer and red blood cell morphology as a biomarker of oxidative stress: a randomized, open label, comparative pilot study
}

\author{
Vasanthi B. ${ }^{1}$, Ainsy Goldlin T. J. ${ }^{2 *}$
}

\begin{abstract}
${ }^{1}$ Department of Pharmacology, Institute of Pharmacology, Madras Medical College, Chennai, Tamil Nadu, India ${ }^{2}$ Department of Pharmacology, Tirunelveli Medical College, Tirunelveli, Tamil Nadu, India

Received: 08 January 2018

Revised: 16 January 2018

Accepted: 31 January 2018

*Correspondence to: Dr. Ainsy Goldlin T. J., Email: ainsygoldlin@gmail.com
\end{abstract}

Copyright: () the author(s), publisher and licensee Medip Academy. This is an openaccess article distributed under the terms of the Creative Commons Attribution NonCommercial License, which permits unrestricted noncommercial use, distribution, and reproduction in any medium, provided the original work is properly cited.

\begin{abstract}
Background: Diabetes mellitus is a major cause of increased morbidity and mortality in developing countries. Foot ulcer is one of the long-term complications of diabetes. Oxidative stress plays a major role in pathogenesis of diabetes mellitus and its long-term complications. Impaired wound healing in diabetic individuals is due to ischemia and hypoxia occurring as a consequence of oxidative stress. Vitamin $\mathrm{C}$ and $\mathrm{E}$ have antioxidant property. Hence the aim and objective of this study was to evaluate the efficacy of Vitamin $\mathrm{C}$ and Vitamin $E$ in healing diabetic foot ulcer.

Methods: 60 adult patients with diabetic foot ulcer were randomized to test and control groups (30 in each). Treatment period was 12 weeks +4 weeks follow up per patient. After obtaining written informed consent, patients in test group received Vitamin C (500mg BD) and Vitamin E (400mg BD) for 12 weeks along with standard treatment for diabetes and antibiotics for foot ulcer.

Results: At the end of 12 weeks, increase in healing of foot ulcer assessed by percent reduction of ulcer area in study group $72.50 \%$ than control group $39.67 \%$ $(\mathrm{p}<0.001)$ was observed. There was a significant reduction of fasting blood glucose, Oxidative stress induced damage to RBCs and BP in the study group compared to control group. No serious adverse effects occurred.

Conclusions: Vitamin $\mathrm{C}$ and $\mathrm{E}$ reverse oxidative stress induced morphological changes in RBCs, improve anemia and increase blood flow to ulcer area. Hence, they are highly effective in healing diabetic foot ulcer along with standard therapy.
\end{abstract}

Keywords: Diabetic foot ulcer, Oxidative stress, Vitamin E, Vitamin C

\section{INTRODUCTION}

Diabetes mellitus is characterized by hyperglycemia, glycosuria, hyperlipidemia and negative nitrogen balance due to decrease in the action of insulin. ${ }^{1}$

Long standing diabetes can lead to many macrovascular and microvascular complications namely cardiovascular, cerebrovascular and peripheral vascular disease, neuropathy, retinopathy and nephropathy. ${ }^{2}$ Non-healing foot ulcer, one of the long-terms complications continues to be a significant healthcare problem and a major cause of morbidity in patients with diabetes. The average risk of foot ulcer development in people with diabetes is estimated to be fifteen percent. ${ }^{3}$ The reported rate of prevalence of diabetic foot ulcer in India was $5.5 \%$. Diabetic patients have a 15-fold higher risk of lower extremity amputation and every 20 seconds a lower limb is lost to diabetes somewhere in the world. Up to $85 \%$ of 
lower limb amputations in diabetic patients are preceded by a foot ulcer., ${ }^{4,5}$

Oxidative stress, an imbalance between production of reactive oxygen species (ROS) and cellular antioxidant defense mechanism play an important role in the pathogenesis of Type 2 diabetes and its long-term complications. ${ }^{6}$ Chronic psychological stress causes persistent elevation of circulating stress hormones like Adrenaline, Glucagon, Corticosteroids etc. and increased production of Free radicals (ROS - Reactive oxygen species). ${ }^{7}$

Chronic stress stimulates the release of Adrenaline from adrenal medulla which in turn stimulates the release of glucagon from $\alpha$ cells and inhibits the release of insulin from $\beta$ cells in pancreas. ${ }^{7,8}$ Adrenaline and glucagon stimulate hormone sensitive lipase (HSL) in adipocytes causing hydrolysis of triacyl glycerol (TAG) into glycerol and free fatty acids (FFA). Glycerol is used in gluconeogenesis and FFAs are used in synthesis of triglycerides, VLDL and LDL in liver. ${ }^{9}$ Glucagon also inhibits the action of insulin by inactivating the glycolytic enzyme Pyruvate kinase. ${ }^{10}$ Thus, there is underutilization and overproduction of glucose leading to hyperglycemia and glycosuria.

Red Blood Cells (RBCs) are the first cells to be exposed to any toxins and they are highly susceptible to oxidative damage as they lack nucleus and mitochondria. Oxidative stress causes cell membrane damage in RBCs leading to formation of crenated edges with rigidity, loss of biconcave shape and denaturation of hemoglobin to form insoluble masses called 'Heinz bodies'. This decreases the oxygen carrying capacity of the red blood cells. ${ }^{10,11}$

RBCs do not require insulin for their glucose uptake and they depend solely on glycolysis for ATP synthesis and metabolic needs. This ATP is required by the ion pumps to maintain the biconcave shape of the RBCs which enables them to slip through the capillaries. Glucagon inhibits glycolysis by inactivating pyruvate kinase enzyme resulting in reduced ATP production. Thus the metabolic needs of the RBCs are left unattended resulting in loss of its biconcave shape. Further the red cell membrane and $\mathrm{RBC}$ shape are also altered, so that it cannot pass through smaller capillaries. ${ }^{10-12}$

The life span of these RBCs are reduced due to phagocytosis by cells of Reticuloendothelial system. This premature lysis and removal of erythrocytes from the circulation results in hemolytic anemia. In response to the ongoing hemolysis, the red cell production (erythropoiesis) increases and an increase in the reticulocytes (immediate precursor of mature RBCs) is apparent in the peripheral circulation. ${ }^{13}$

The ROS catalyse the production of Eicosanoid isomers through non-enzymatic oxidation of Arachidonic acid. The NSAIDs cannot inhibit this non-enzymatic production of
Isoprostanes but antioxidants suppress the synthesis of isoprostanes. F2 isoprostanes are one of the best characterized iso-eicosanoids. 8-iso PGF2 $\alpha$ also binds to the prostanoid receptors and induces chronic inflammation. It can also cause direct cell damage including $\beta$ cell damage. It promotes platelet adhesion and activation, antagonises the action of Nitric oxide resulting in vasoconstriction. ${ }^{12,14}$

Elevated levels of isoprostanes especially 8-iso PGF2 $\alpha$ significantly correlated with high blood glucose. The circulating isoprostanes bind to the insulin receptor and prevent the recruitment of Glucose transporter-4 (GLUT4) to the cell membrane thereby inhibiting the transport of glucose into the cell. Thus isoprostanes antagonise the effect of insulin causing hyperglycemia. ${ }^{12,14,15}$

Diabetic foot ulcer refers to a full thickness wound below the level of ankle in patients with diabetes. ${ }^{16}$ They are commonly seen on the plantar aspect of the foot especially on the heel and the ball of the foot. They have a punched out edge with slough in the floor and the base is slightly indurated. They are less painful and the surrounding skin has reduced or absent sensation. ${ }^{17}$ Infection with gram positive, gram negative and anaerobic organisms are common in diabetic limb. Management of diabetic foot ulcer includes local wound care, eradication of infection, restoration of blood flow and treatment of painful neuropathy. If the diabetic foot ulcer is left untreated or undertreated non-healing ulcer, gangrene, osteomyelitis and necrotizing fascitis can occur which have a potential to culiminate in amputation, a most devasting complication of diabetes. ${ }^{18}$

Peripheral neuropathy along with ischemia play a vital role in development of foot ulcer in individuals with diabetes. Involvement of sensory, motor and autonomic fibres lead to loss of sensations, callus formation, appearance of fissures and cracks that act as a portal of entry of infection with subsequent onset of foot ulcers. Autonomic dysfunction also cause microcirculatory abnormalities leading to nutrient and oxygen deprivation of the tissues. ${ }^{18}$

Peripheral vascular disease and hemolytic anemia cause ischemia and tissue hypoxia which in turn contribute to the development of foot ulcer.

Under physiological conditions, there is a balance between the endogenous vasodialators (NO, Prostacyclin) and vasoconstrictors (Endothelin-1, Thromboxane $\mathrm{A}_{2}$ and Prostaglandin $\mathrm{H}_{2}$ ). The ROS reduce the bioavailability of Nitric oxide (NO) in the endothelium (EDRF) by reacting chemically with $\mathrm{NO}$ to produce peroxynitrite $\left(\mathrm{ONOO}^{-}\right)$. The balance between the endogenous vasodilators and vasoconstrictors is thus disturbed resulting in endothelial dysfunction and peripheral vascular disease causing impaired tissue perfusion with subsequent ulcer formation. ${ }^{19}$ 
Anemia, peripheral vascular disease, microcirculatory abnormalities and neuropathy contribute to the development of non-healing foot ulcer and gangrene in spite of meticulous glycemic control. ${ }^{4}$

Vitamin C (Ascorbic Acid) serves as an antioxidant in several non-enzymatic reactions, donates electrons which efficiently scavenges ROS (free radicals) and inhibits lipid peroxidation. It also promotes regeneration of Vitamin $\mathrm{E}$ and Reduced Glutathione.Vitamin $\mathrm{C}$ preserves NO dependent endothelial vasodilataion by competing with NO for superoxide ion. It also helps in collagen biosynthesis and wound healing. ${ }^{20,21}$

Vitamin E ( $\alpha$-tocopherol) is the major antioxidant present in cell membranes. It prevents non-enzymatic oxidation of various cell components by molecular oxygen and free radicals such as superoxide $\left(\mathrm{O}_{2}^{-}\right)$and hydrogen peroxide $\left(\mathrm{H}_{2} \mathrm{O}_{2}\right)$. It inhibits lipid peroxidation by protecting the polyunsaturated fatty acids and thus maintains the structural integrity of the cells especially red blood cells. The chromanol nucleus of tocopherols donates its phenolic hydrogen to reduce the free radical and is itself oxidized to the quinone form. The phenoxy radical thus formed reacts with Vitamin $\mathrm{C}$ to regenerate tocopherol. Hence there is a synergistic action when Vitamin $\mathrm{C}$ and $\mathrm{E}$ are given together. Vitamin $\mathrm{E}$ also reduces platelet adhesion, aggregation and increases NO bioavailability. Thus Vitamin C and E improve blood supply, correct tissue hypoxia and promote wound healing. ${ }^{22}$

In this study Vitamin C and Vitamin E were given as add on treatment to reduce insulin resistance, hyperglycemia, correct hemolytic anemia and to heal diabetic foot ulcer. $\mathrm{RBC}$ morphology was used as a biomarker for oxidative stress.

\section{Objectives}

Primary objective: was to evaluate the efficacy of Vitamin $\mathrm{C}$ and Vitamin $\mathrm{E}$ as add on therapy in healing diabetic foot ulcer.

Secondary objective: was to evaluate the morphological changes in the RBCs due to oxidative stress and reversal of these changes with Vitamin $\mathrm{C}$ and Vitamin $\mathrm{E}$ and to assess the improvement in glycemic control and hemoglobin level.

\section{METHODS}

The study was conducted at Institute of Surgery, Madras Medical College and Rajiv Gandhi Government General Hospital, Chennai from October 2015 to June 2016.

\section{Study design}

It was conducted as a Randomized, Open label, Comparative Pilot study in 60 adult patients (30 patients in control group and 30 patients in study group) diagnosed with diabetic foot ulcer and on standard treatment.

\section{Inclusion criteria}

Patients of either sex diagnosed with Diabetic foot ulcer (Grade 1 and 2) having Type 2 Diabetes Mellitus for $>5$ years and on standard treatment (Insulin and/or Oral Hypoglycemic agents) falling in the age group 40-70 years and willing to give written informed consent were included in the study.

\section{Exclusion criteria}

Patients with blood pressure $>160 / 100 \mathrm{mmHg}$, co-existing liver disease, renal disease, malignancy, any hematological disorder, Current or ex-smokers, those who are on beta blockers and anticoagulants were excluded.

\section{Study procedure}

The study was conducted for 16 weeks including 12 weeks study period and 4 weeks of post treatment follow up per patient. 126 patients were screened by History, General Examination, systemic examination and Lab investigations, out of which 60 patients who fulfilled the eligibility criteria were recruited. The purpose, procedures and benefits of the study were explained to them and written informed consent was obtained from the subjects who were willing to participate in the trial in Tamil and English.

The enrolled patients were randomized by simple randomization into control and study group and received respective therapies. Patients in Control group $(n=30)$ received standard treatment for diabetes - Oral hypoglycaemic agents and/or Insulin and for diabetic ulcer - Metronidazole and Ciprofloxacin (short course of 7 to 10 days). Patients in Study group $(\mathrm{n}=30)$ received standard treatment plus one tablet of Vitamin C $-500 \mathrm{mg}$ and one capsule of Vitamin E -400 mg each twice daily. The patients received the study medication for 4 weeks at a time and were asked to review at the end of 4 weeks, 8 weeks and 12 weeks with the empty blister packs to check compliance. They were followed up for a post treatment period of 4 weeks, without the study drugs. After the completion of 16 weeks study period, the patients were provided appropriate medical care. Any adverse event reported by the patient or observed by the physician during the study was recorded and appropriate medical care was given. During the study period the subject was allowed to withdraw his/her voluntary consent and opt out of study.

\section{Assessment}

The following parameters were taken for assessment in this study.

- Foot ulcer: The size of foot ulcer was measured before starting the patients on the study drugs and 
during subsequent visits. Healing of foot ulcer was assessed by percent reduction in foot ulcer area.

- Morphological changes in RBCs: $1 \mathrm{ml}$ of the patient's blood was centrifuged at $3000 \mathrm{rpm}$ for 5 minutes. The supernatant was discarded and the packed cells diluted with equal volume of $0.9 \%$ normal saline and centrifuged again. The supernatant was again discarded and the packed cells reconstituted as $10 \%$ $\mathrm{v} / \mathrm{v}$ suspension with $0.9 \%$ normal saline and a drop of this suspension was put on a glass slide under a cover slip and studied under high power microscope. 100 RBC's were viewed and the number of Crenated RBCs with Heinz bodies and reticulocytes were counted for each patient in both the groups at each visit and recorded as a percentage. ${ }^{12}$

- Glycemic control was assessed based on fasting blood sugar levels

- Hemoglobin levels and RBC count were recorded at each visit to assess improvement in anemia.

\section{Statistical analysis}

Statistical analysis was done using SPSS vs 21. P value $<0.05$ was considered to be statistically significant. Distribution of age and sex were analyzed using one way ANOVA and Pearson chi- square test respectively. The difference within the groups in hemoglobin level, RBC count, RBC morphology, Systolic and Diastolic blood pressure and percent reduction in foot ulcer area were analyzed using students paired t-test. Similarly the difference between the control and test groups was analyzed using independent t-test. The differences in the biochemical investigations performed at baseline and at the end of 12 weeks were analyzed using student's paired t- test.

\section{RESULTS}

All patients completed the study and results analyzed were mentioned as follows.

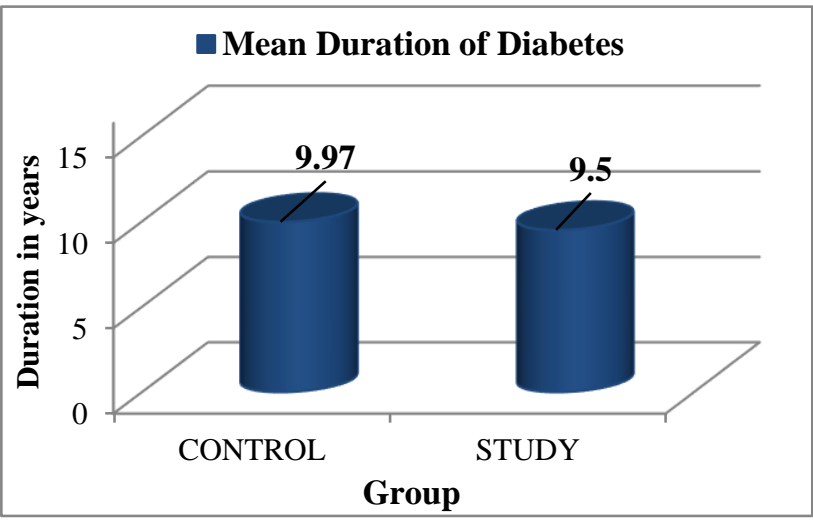

Figure 1: Mean duration of diabetes mellitus.

Figure 7 shows the number of patients with anemia $(\mathrm{Hb}$ $<12 \mathrm{~g} / \mathrm{dL})$. Majority of patients in both the groups had anemia $(\mathrm{Hb}<12 \mathrm{~g} / \mathrm{dL})$ at the beginning of the study.

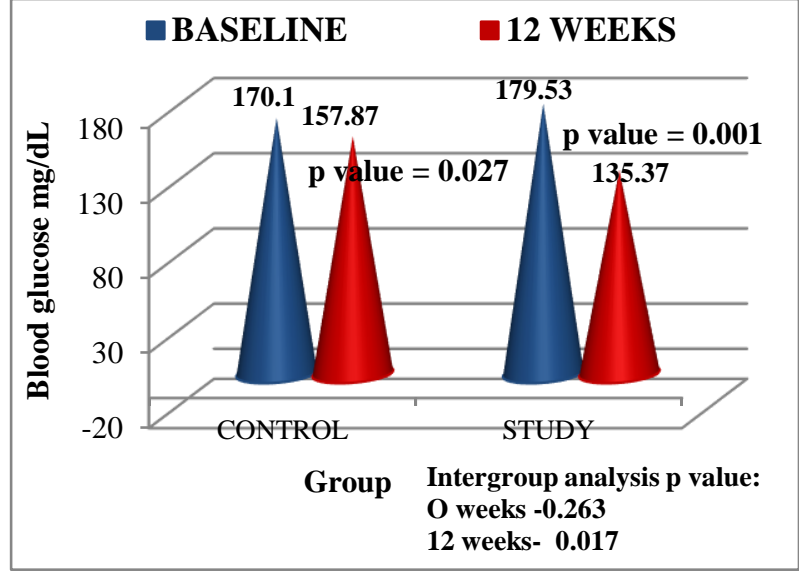

Figure 2: Mean fasting blood glucose (mg/dl).

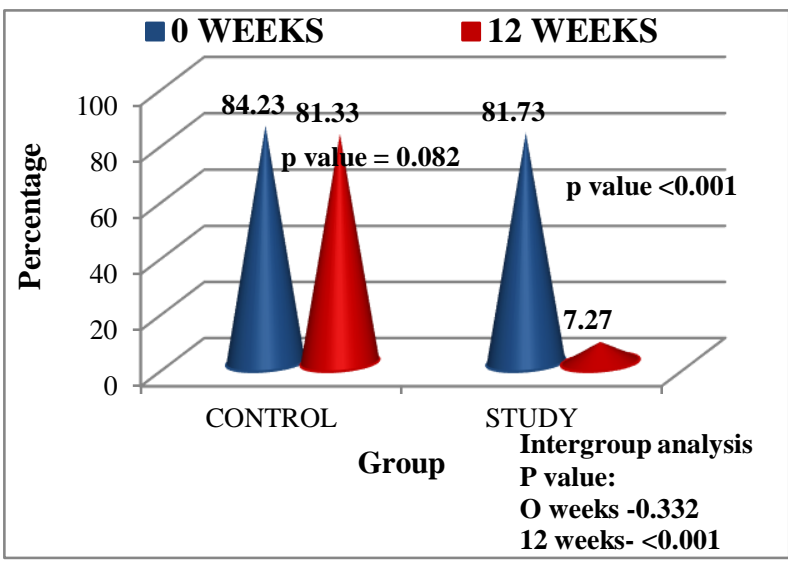

Figure 3: Mean percentage of crenated red blood cells with Heinz bodies.

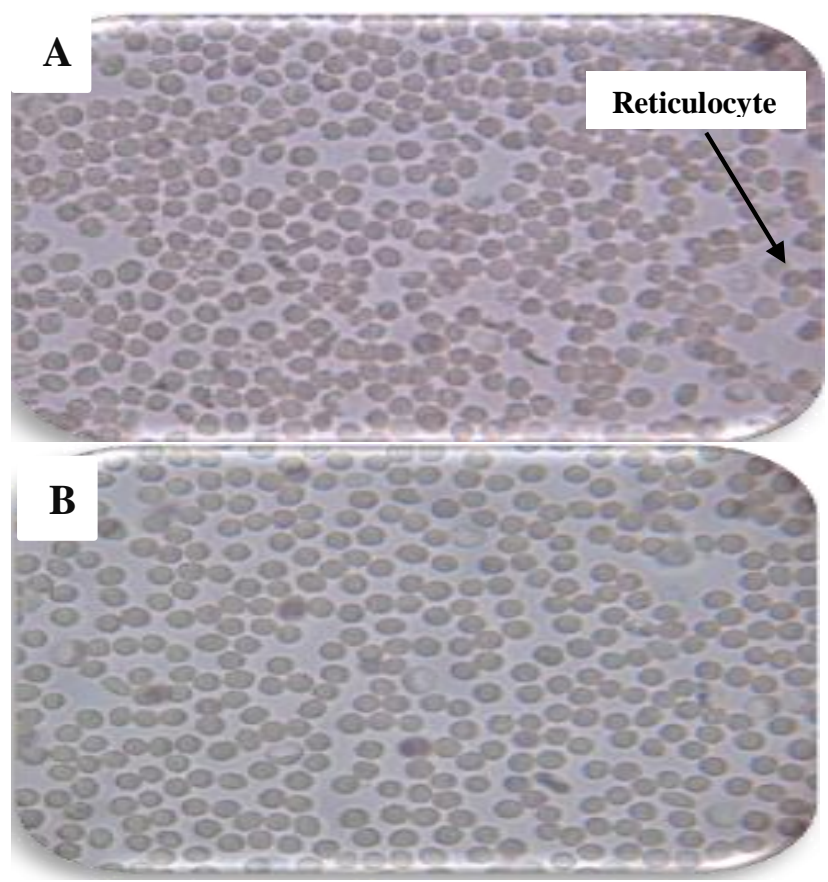

Figure 4: (A, B) Morphology of RBCs before and after treatment. 


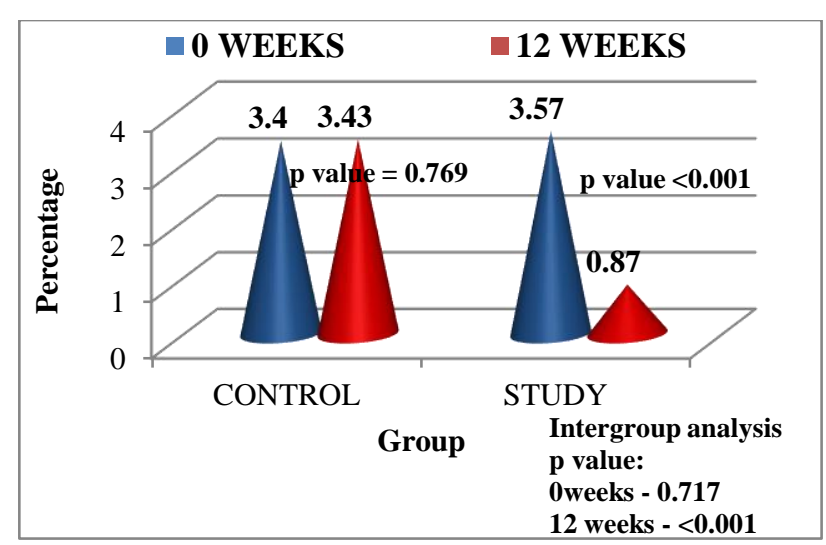

Figure 5: Mean percentage of reticulocytes.

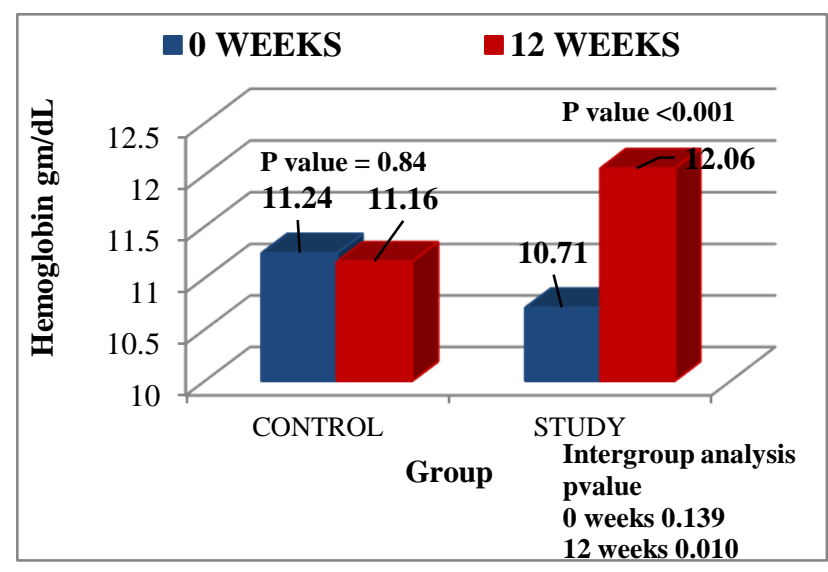

Figure 6: Mean hemoglobin (g/dL).

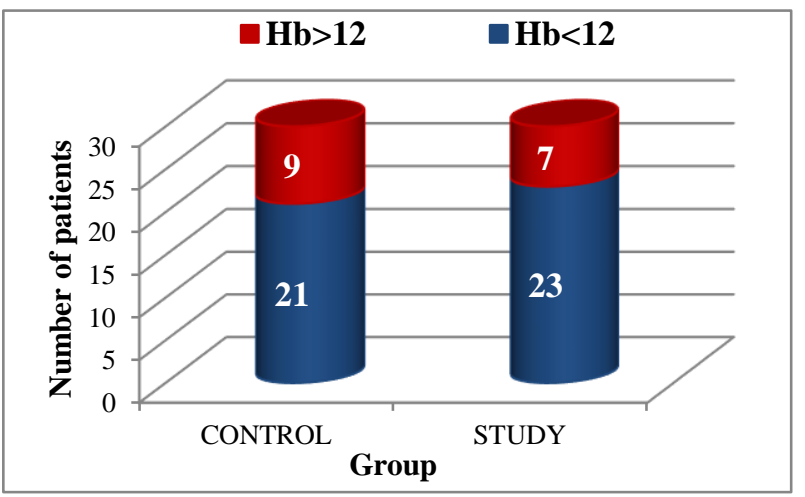

Figure 7: Incidence of anemia (hemoglobin $<12 \mathrm{~g} / \mathrm{dL}$ ).

Table 1: Mean percent reduction (healing) in foot ulcer area at the end of 4 weeks and 12 weeks (\%).

\begin{tabular}{|llllll|}
\hline \multirow{5}{*}{ Group } & $\begin{array}{l}\mathbf{4} \\
\text { weeks }\end{array}$ & $\begin{array}{l}\mathbf{1 2} \\
\text { weeks }\end{array}$ & $\begin{array}{l}\mathbf{4} \\
\text { weeks }\end{array}$ & $\begin{array}{l}\mathbf{1 2} \\
\text { weeks }\end{array}$ & $\begin{array}{l}\text { P } \\
\text { value }\end{array}$ \\
\cline { 2 - 6 } & $\begin{array}{l}\text { Mean } \\
(\boldsymbol{\%})\end{array}$ & SD & $\begin{array}{l}\text { Mean } \\
(\boldsymbol{\%})\end{array}$ & SD & \\
\hline Control & 13.53 & 8.89 & 39.67 & 14.97 & 0.018 \\
\hline Study & 20.40 & 14.37 & 72.50 & 13.10 & $<0.001$ \\
\hline P value & 0.047 & & $<0.001$ & & \\
\hline
\end{tabular}

SD: Standard deviation

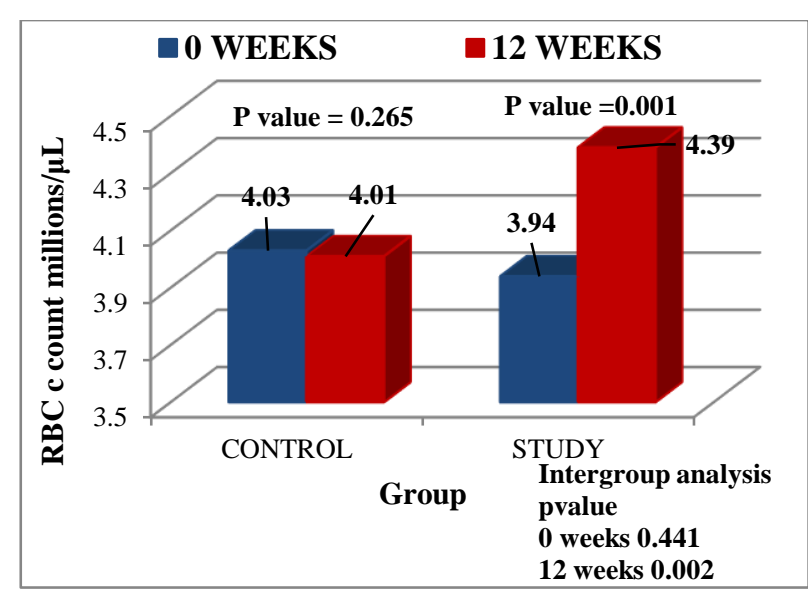

Figure 8: Mean RBC count.

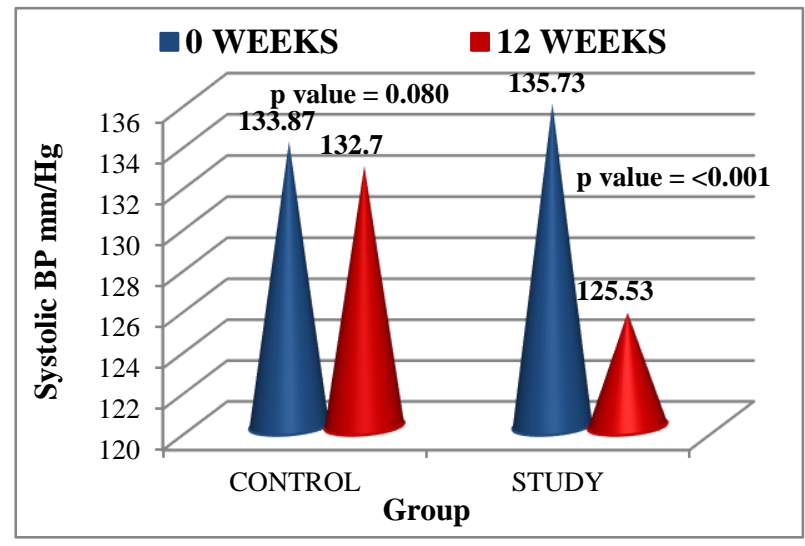

Figure 9: Mean systolic blood pressure (mm/Hg).

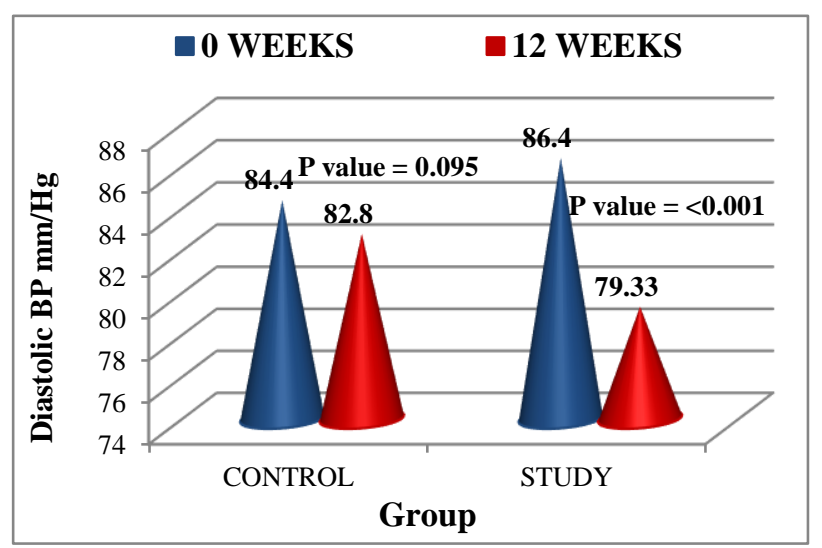

Figure 10: Mean diastolic blood pressure (mm/Hg).

Table 1 shows the healing of foot ulcer assessed by mean percent reduction of foot ulcer area at the end of 4 weeks and 12 weeks.

At baseline, the percent reduction was assumed to be zero. In the control group, the percent reduction in foot ulcer area was $13.53 \%$ at 4 weeks and $39.67 \%$ at 12 weeks $(\mathrm{p}=$ $0.018)$. In the Study group the percent reduction in foot ulcer area was $20.40 \%$ at 4 weeks and $72.50 \%$ at 12 weeks $(\mathrm{p}<0.001)$. 


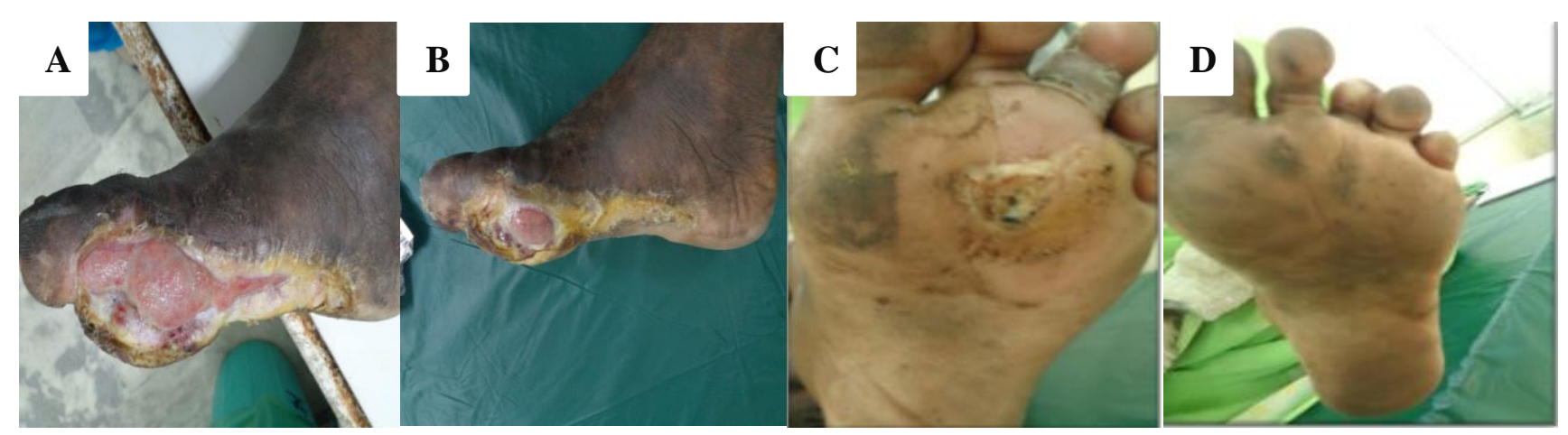

Figure 11: (A, B, C, D) Diabetic foot ulcer before and after treatment.

Table 2: Adverse event profile.

\begin{tabular}{|lll|}
\hline Adverse event & Control group & Study group \\
\hline Nausea & 2 & 2 \\
\hline Abdominal pain & 2 & 1 \\
\hline Diarrhoea & 2 & 1 \\
\hline Hypoglycemia & 2 & 2 \\
\hline Metallic taste & 3 & 2 \\
\hline
\end{tabular}

Table 3: Incidence of adverse drug reactions.

\begin{tabular}{|lll|}
\hline Group & $\begin{array}{l}\text { Control } \\
\text { group }(\mathbf{N}=\mathbf{3 0})\end{array}$ & $\begin{array}{l}\text { Study group } \\
(\mathbf{N}=\mathbf{3 0})\end{array}$ \\
\hline No. of adverse events & $11(33 \%)$ & $8(27 \%)$ \\
\hline
\end{tabular}

\section{DISCUSSION}

Non-healing foot ulcer is one of the most serious complications of diabetes mellitus that occurs in spite of medical management. ROS cause chronic inflammation, insulin resistance, RBC damage (hemolytic anemia) and endothelial dysfunction (peripheral vasospasm). Oxidative stress followed by chronic inflammation and hemolytic anemia are the major factors that play a vital role in the pathogenesis of micro and macro-vascular complications and non-healing foot ulcer of type 2 diabetes.

Therefore, supplementation of antioxidants like Vitamin C and Vitamin E can reduce inflammation and RBC damage along with reversal of insulin resistance and endothelial dysfunction (by increasing bioavailability of NO) accelerating the healing process in diabetic foot ulcer.

In this study, 126 patients diagnosed with diabetic foot ulcer on treatment for diabetes (more than 5 years duration) were screened initially. 60 patients who fulfilled the eligibility criteria were randomized into control and study groups of 30 patients in each group and received their corresponding treatments. The mean age was 55.47 years in the control group and 53.57 years in the study group. A high proportion of male patients in both control (70\%) and study $(66.67 \%)$ groups was noted. The mean duration of diabetes was found to be 9.97 years in control group and 9.50 years in the study group. This implies that complications like foot ulcer occur due to longstanding diabetes.

At 0 week, the mean fasting blood glucose was above average and comparable in both the groups of our study. At the end of 12 weeks of study period, the mean fasting blood glucose was found to be $157.87 \mathrm{mg} / \mathrm{dL}$ ( $\mathrm{p}=0.027$ ) in control group and $135.37 \mathrm{mg} / \mathrm{dL}(\mathrm{p}=0.001$ in study group. Intergroup analysis showed that there was a statistically significant reduction in fasting blood glucose $(p<0.001)$ between the control and study groups at the end of 12 weeks. This shows that supplementing antioxidants to standard treatment regimen results in better control of blood glucose levels. ${ }^{23}$

At the beginning of the study, nearly 81 percentage (\%) crenated red blood cells (RBCs) with Heinz bodies were found both in the control and study groups. This indicates free radical induced damage to RBCs in patients with diabetic foot ulcer. At the end of 12 weeks, the percentage of crenated RBCs with Heinz bodies was reduced significantly in the study group $(7.27 \%, \mathrm{p}<0.001)$ while compared to that of control group $(81.33 \%, \mathrm{p}=0.082)$. This clearly indicates that antioxidants improve membrane integrity of RBCs. reduces fragility and hemolysis by preventing free radical induced oxidative damage. ${ }^{12}$

At 0 week, the percentage of reticulocytes was $3.40 \%$ in control group and $3.57 \%$ in study group. By the end of 12 weeks, there was a statistically significant decrease of reticulocytes in the study group $(0.87 \%, \mathrm{p}<0.001)$ but not in the control group $(3.43 \%, \mathrm{p}=0.769)$. This shows that antioxidants decrease accelerated erythropoiesis and reticulocytes due to free radical induced hemolysis. ${ }^{12}$

The mean haemoglobin $(\mathrm{Hb})$ was below average in both the control $(11.24 \mathrm{~g} / \mathrm{dl})$ and study groups $(10.71 \mathrm{~g} / \mathrm{dl})$ at 0 week. After 12 weeks treatment, the control group did not show any significant change $(11.16 \mathrm{~g} / \mathrm{dL}, \mathrm{p}=0.84)$ but the study group showed a significant increase in $\mathrm{Hb}$ $(12.06 \mathrm{~g} / \mathrm{dL}, \mathrm{p}<0.001)$. The mean total RBC count was also significantly increased in the study group from 3.94 million $/ \mu \mathrm{L}$ at 0 week to 4.39 million $/ \mu \mathrm{L}$ at $12^{\text {th }}$ week 
( $p=0.0001)$, while there was no statistically significant difference in the control group ( 0 week -4.03 million $/ \mu \mathrm{L}$, 12 weeks -4.01 million $/ \mu \mathrm{L}, \mathrm{p}=0.265$ ). This proves that the type of anemia in type 2 diabetes is free radical induced hemolytic anemia and antioxidants reverse this hemolytic anemia. $^{12}$

The mean BP was slightly above average in both the groups at baseline. At the end of 12 weeks there was a statistically significant reduction in systolic $(125.53 \mathrm{mmHg}, \mathrm{p}<0.001)$ and diastolic $(79.33 \mathrm{mmHg}$, $\mathrm{p}<0.001) \mathrm{BP}$ in the study group compared to the control group. This may be attributed to the improvement in blood circulation and reduction in total peripheral resistance by protecting NO from free radical induced inactivation in blood vessels. In the Central nervous system, the availability of NO is increased which restores the balance between sympathetic and parasympathetic nervous system. 6

In the control group, the healing of foot ulcer assessed by percent reduction in foot ulcer area was $13.53 \%$ at 4 weeks and $39.67 \%$ at 12 weeks $(\mathrm{p}=0.018)$. In the Study group the percent reduction in foot ulcer area was $20.40 \%$ at 4 weeks and $72.50 \%$ at 12 weeks $(p=0.001)$. Intergroup analysis showed that there was a statistically significant difference in wound healing $(\mathrm{p}<0.001)$ between the groups at the end of 12 weeks. This implied that the study group showed accelerated healing of foot ulcer which may be attributed to antioxidants that reverse endothelial dysfunction and improves blood flow by protecting nitric oxide against free radical induced inactivation and provide sufficient oxygenation to the tissues by protecting the RBCs against free radical induced damage and hemolysis. The chronic inflammation induced by free radicals which increases the production of inflammatory mediators like $\mathrm{PGF}_{2 \alpha}$ is reduced by the antioxidants. ${ }^{14,15}$

There was no change in other biochemical parameters like Blood urea, Serum Creatinine, Bilirubin, Aspartate transaminase and Alanine transaminase in both the groups during the study period.

All the mentioned effects were sustained in the study group at the end of 4 week follow up period indicating that the beneficial effects of antioxidants persist for some time even after its withdrawal.

After one month of treatment with antioxidants the hemolysis of RBCs was decreased. The blood flow to the ulcer area was restored and induced wound healing. During the follow up period of 4 weeks, there was a sustained reduction in blood glucose level and hemolysis of RBCs. The wound healing was almost complete. This proves the fact that free radical injury causes tissue damage, ischemia and hypoxia leading to diabetic foot ulcer and treatment with antioxidants like Vitamin $\mathrm{E}$ and Vitamin $\mathrm{C}$ increased blood flow to the ulcer area and enhanced wound healing.

\section{CONCLUSION}

Oxidative stress induced chronic inflammation in type 2 diabetes is the most important cause for long-term complications like nephropathy, retinopathy, neuropathy and diabetic foot ulcer.

Ischemia, hypoxia and inflammation along with neuropathy are responsible for ulcer foot in type 2 diabetes. This hypothesis is proved by giving antioxidants like Vitamin $\mathrm{C}$ and Vitamin $\mathrm{E}$ as add on treatment in patients with diabetic foot ulcer, using RBC morphology as a biomarker of oxidative stress.

The hemolytic anemia improved within one month followed by healing of foot ulcers which was almost complete at the end of 12 weeks proving the fact that correction of anemia improved blood flow accelerated the healing process of ulcer.

Therefore, Vitamin C and Vitamin E can be added to the standard treatment in diabetic ulcer foot and they also act as a disease modifying agent by reducing insulin resistance.

This improves the quality of life of patients and saves the leg from amputation.

\section{ACKNOWLEDGEMENTS}

Authors would like to acknowledge to the Institute of General Surgery, Rajiv Gandhi Government General Hospital and Madras Medical College and for all the study participants for their active participation.

Funding: No funding sources

Conflict of interest: None declared

Ethical approval: The study was approved by the Institutional Ethics Committee of Madras Medical College, India

\section{REFERENCES}

1. KD Tripathi, eds. Essentials of Medical Pharmacology, $7^{\text {th }}$ Ed. New Delhi, Jay Pee brothers Medical Publishers; 2013:258.

2. Funk JL. Disorders of endocrine pancreas. In: Gary D. Hammer, Stephen J McPhee, eds Pathophysiology of Disease - An introduction to Clinical Medicine, $7^{\text {th }} \mathrm{Ed}$. New York, Mc Graw Hill; 2014:517-539.

3. Zubair M, Malik A, Ahmad J. Diabetic foot ulcer: A review, American Journal of Internal Medicine. 2015;3(2):28-49.

4. Ganchi PA, Eriksson E. Diabetes Mellitus and Wound Healing In: C. Ronald Kahn, Gordon C. Weir, George L. King, Alan C. Moses, Robert J. Smith, Alan M. Jacobson; eds Joslin's Diabetes Mellitus, $14^{\text {th }}$ Ed. Lippincott Williams and Wilkins; 2005:1133-1138.

5. Cancelliere P. Current Epidemiology of Diabetic Foot Ulcers, International J of Diabetes. 2016;1(1):1-3. 
6. Ayepola OR, Brooks NL, Oguntibeju OO. Oxidative Stress and Diabetic Complications In: Oluwafemi O. Oguntibeju; eds. The Role of Antioxidant Vitamins and Flavonoids Antioxidants- Antidiabetic Agents and Human health, AvE4EvA (PDF); 2014:25-34.

7. Subramaniyam S, Kutty KM, Singh HD. eds. Textbook of Human Physiology, $6^{\text {th }}$ Ed, New Delhi, S. Chand and Company; 2001:481-563.

8. Tripathi KD, eds. Essentials of Medical Pharmacology, 7th ed. New Delhi, Jay Pee brothers Medical Publishers; 2013:130.

9. Ferrier DR, eds. Fatty acid, Ketone Body and Triacylglycerol Metabolism In: Lippincott's Illustrated Reviews Biochemistry $6^{\text {th }}$ Ed, Philadelphia, Lippincott Williams and Wilkins; 2014:190.

10. Ferrier DR, eds. Introduction to metabolism and Glycolysis In: Lippincott's Illustrated Reviews Biochemistry $6^{\text {th }}$ Ed, Philadelphia, Lippincott Williams and Wilkins; 2014:102-103.

11. Ferrier DR. eds. Pentose phosphate pathway and Nicotinamide Adenine Dinucleotide Phosphate In: Lippincott's Illustrated reviews Biochemistry $6^{\text {th }} \mathrm{Ed}$, Philadelphia, Lippincott Williams and Wilkins; 2014:152-153.

12. Vasanthi B, Mathew RA. Red Blood Cell Morphology as a marker of Oxidative stress in Type 2 Diabetes and Efficacy of Antioxidants as add on therapy to standard treatment- A Randomized, Open label, Comparative Pilot Study, International Journal of Institutional Pharmacy and life sciences. 2017;7(1):55-71.

13. Glader B, Greer JP, Arber DA, eds. Hereditary Hemolytic Anemias Due to Red Blood Cell Enzyme Disorders In: Wintrobe's Clinical Hematology, 12 $2^{\text {th }}$ Ed. Philadelphia, Lippincott Williams and Wilkins, Chapter 32;2009.

14. Kaviasrasan S, Muniandy S, Qvist R, Ismail IS. F2Isoprostanes as novel biomarkers for Type 2 Diabetes: A Review, J Clin Biochem Nutr. July 2009;45:1-8.

15. Smyth EM, Grosser T, FitzGerald GA. Lipid-derived autacoids: eicosanoids and platelet-activating factor.
Goodman \& Gilman's The Pharmacological Basis of Therapeutics, $12^{\text {th }}$ Edn, eds Brunton L, Chabner B, Knollman B. McGraw-Hill. New York. 2011:937957.

16. Hinchliffe RJ, Schaper NC, Thompson MM, Tripathi $\mathrm{RK}$, Timaran $\mathrm{CH}$, eds. The Diabetic Foot, United Kingdon, JP Publishers; 2014:3-6.

17. Das S, eds. A manual on Clinical Surgery, $7^{\text {th }}$ Ed. Kolkata, Das; 2008;51-52.

18. Seshiah V, Balaji V, Balaji M, Patel M, eds. A handbook on diabetes mellitus, $4^{\text {th }}$ Ed, New DelhiChennai, All India Publishers and Distributors; 2009:296-307.

19. Seshiah V, Balaji V, Balaji M, Patel M, eds. A handbook on diabetes mellitus, 4th Ed, New DelhiChennai, All India Publishers and Distributors; 2009:178-179.

20. Combs GF, eds. Vitamin C In: The Vitamins, Fundamental Aspects in Nutrition and Health, 4thed. London, Elsevier; 2012:233-261.

21. Free radicals and Antioxidants In: Satyanarayana U, Chakrapani U; eds. Biochemistry, $3^{\text {rd }}$ Ed. Kolkata, Books and Allied; 2006:655-661.

22. Combs GF, eds. Vitamin E In: The Vitamins, Fundamental Aspects in Nutrition and Health. 4thed, London, Elsevier; 2012:187-211.

23. Vasanthi B, Ali YAS. Effect of $\alpha$-tocopherol and ascorbic acid in reducing the insulin resistance of early type 2 diabetes mellitus patient: An open label randomized controlled study. International Journal of Institutional Pharmacy and Life Sciences. 2015;5(4):38-51.

Cite this article as: Vasanthi B, Goldlin ATJ. Efficacy of Vitamin $\mathrm{C}$ and Vitamin $\mathrm{E}$ as an add on therapy in diabetic foot ulcer and red blood cell morphology as a biomarker of oxidative stress: a randomized, open label, comparative pilot study. Int J Basic Clin Pharmacol 2018;7:548-55. 